\title{
Stray Pin Capacitance Effects on Signal Reading Coupled by Optocoupler on Microcontroller Boards
}

\author{
Albertus N. Rumawas \\ Department of Mechanical Engineering \\ Swiss German University \\ Tangerang 15143, Indonesia \\ Email: anrumawas@gmail.com
}

\author{
Edi Sofyan \\ Department of Mechanical Engineering \\ Swiss German University \\ Tangerang 15143, Indonesia
}

\begin{abstract}
Reading high frequency signal could have possibility effecter by the internal capacitance from microcontroller pins. Study case is between Arduino and encoder coupler with optocouplers. High frequency signal is struggle to high logic due to slower rise time. Turns out slower rise time caused by internal capacitance causing 1st order response system, by adding pull-up resistor on input pin, rise time could be reduce. As final result, adding pull-up resistor does affecting the rise time, but the there are still other factors beside internal capacitance.
\end{abstract}

Keywords: Arduino, Optocoupler, Encoder, Frequency.

\section{INTRODUCTION}

Obtaining good feedback from encoder is crucial in calculating position, speed, and acceleration. It is often to have encoder that have different working potential with the microcontroller. Putting optocouplers and pull-up resistors could accommodate to passing signal from two different potential. This coupling method cause signal problem at high frequency. Signal that passed from optocoupler is not reach the minimum voltage to set logic into high condition. It was observed that higher the input frequency at optocouplers, the output signal become more distorted. This problem is could result reading problem in microcontroller, accumulate error in long term running, or direct system failure. Adding proper pull-up resistor could reduce distortion on passed signal.

\section{InVESTIGATION METHODOLOGY}

The experiment was simulated by using 2 Arduino Mega, optocouplers, and oscilloscope to shown the signal. first $\mathrm{Ar}-$ duino Mega was acting as a signal generator, signal frequency could be varied by using program. Second Arduino was acting as a signal receiver, both Arduino Mega coupled by optocoupler Figure 1 Oscilloscopes probe is attached on second Arduino between receiver pin and receiver GND.

Since Arduino that produce pulse needs to make signal frequency as high as possible. The Arduino was programmed using Direct Memory Access (DMA) to avoid unnecessary processing time, using DMA could increasing the generated frequency up to $500 \mathrm{kHz}$ compare to $29 \mathrm{kHz}$ while using standard programming command. DMA was almost $30 \%$ faster to be execute compare to standard programming language

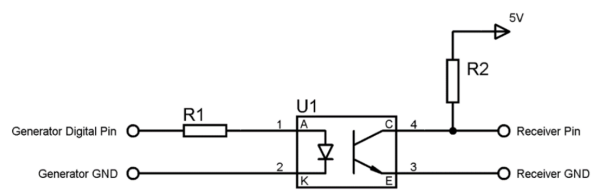

Fig. 1. Testing Circuit Assembly.

Figure 2. For experiment $1 \mathrm{kHz}$ signal was generated from the Arduino.

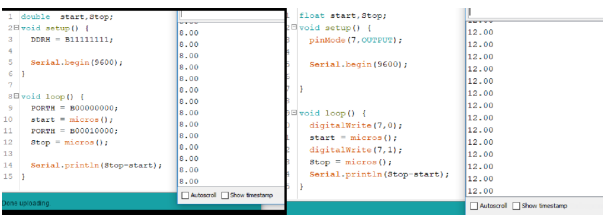

Fig. 2. DMA processing time (left) Standard processing time (right).

Output signals that shown on oscilloscope after probes are attached were not in good form, it was observe that signal was depended on pull resistor value.

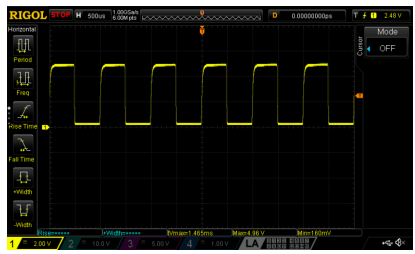

Fig. 3. $1 \mathrm{kHz}$ signal with $3.3 \mathrm{k} \Omega \pm 5 \%$ pull-up resistor.

Signal shown on oscilloscope was a transient respond (Figures 3-5). This signal commonly generated by combining resistor and capacitor with give known equation (1). $T$ does time need by the system to reach $63 \%$ of the steady state 


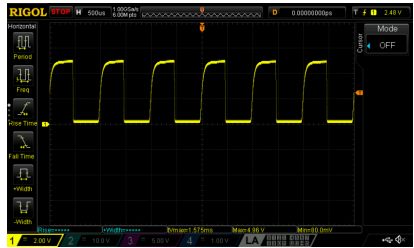

Fig. 4. $1 \mathrm{kHz}$ with $10 \mathrm{k} \Omega \pm 5 \%$ pull-up resistor.

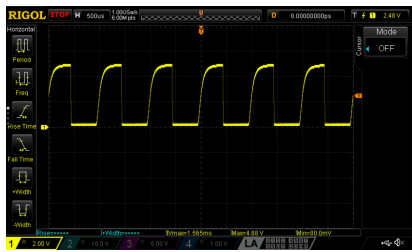

Fig. 5. $1 \mathrm{kHz}$ with $20 \mathrm{k} \Omega \pm 5 \%$ pull-up resistor.

condition, this could be measured by using oscilloscope. $R$ is pull-up resistor value, and $C$ is value of pin capacitance. By rearrange the variables, $C$ could be found:

$$
T=R \times C
$$

where: $T=$ Responds Time (s), $R=$ Responds Value $(\Omega)$, $C=$ Capacitor Value $(\mathrm{F})$.

Input signal is generated by fix frequency, $100 \mathrm{kHz}$, with period of $\mathrm{T}=10 \mu \mathrm{s}$ for one complete wave. $5 \mu$ s during high state and $5 \mu$ s during low state condition. Since the controller need to detected high state in time range of high state condition. This resulting in time range of $5.0 \mu \mathrm{s}$. The pulses should reach maximum value to set high logic.

$$
V_{C}=V_{S} \times\left(1-e^{-\frac{t}{\tau}}\right)
$$

where: $V_{C}=$ Voltage across capacitor, $V_{S}=$ Supply Voltage, $t=$ Elapsed Time, and $\tau=$ Time Constant $(R \times C)$.

Equation (2). could be rearrange to find $\mathrm{R}$ into equation (3)., with $\mathrm{Vc}=5$ Volt as final voltage value to set high logic, 5 $\mu$ s as time to reach final value, T substituted with $\mathrm{RC}$, and $\mathrm{C}$ will come from equation (1).

$$
\begin{aligned}
\ln (0.4) & =-t(R C)^{-1} \\
R & =t(0.9 C)^{-1}
\end{aligned}
$$

where: $t=$ Elapsed Time, $C=$ Pin Capacitance $(F)$, and $R$ $=$ Resistor Value $(\Omega)$.

\section{INVESTIGATION RESULT}

Output signal was shown on oscilloscope, time needed to reach $63 \%$ from steady state or first-time constant was measured using oscilloscope function. To calculate value of $\mathrm{C}, 3$
TABLE I

Time Constant Measurement and Pin Capacitance Calculation

\begin{tabular}{llllll}
\hline $\begin{array}{l}\text { Rated } \\
\text { pullup } \\
\text { resistor } \\
(\mathrm{k} \Omega)\end{array}$ & $\begin{array}{l}\text { Measured } \\
\text { pullup } \\
\text { resistor }(\mathrm{k} \Omega)\end{array}$ & $\begin{array}{l}\text { Time } \\
\text { reach } \\
(\mu \mathrm{s})\end{array}$ & $\begin{array}{r}\text { to } \\
63 \%\end{array}$ & $\begin{array}{l}\text { Current Flow } \\
(\mathrm{mA})\end{array}$ & $\begin{array}{l}\text { Pin Ca- } \\
\text { pacitance } \\
\text { value }(\mathrm{nF})\end{array}$ \\
\hline $10 \pm 5 \%$ & 9.88 & 48 & 0.51 & 4.86 \\
$15 \pm 5 \%$ & 14.75 & 68 & 0.34 & 4.61 \\
$20 \pm 5 \%$ & 19.85 & 84 & 0.25 & 4.23 \\
\hline & & & Average & 4.57 \\
\hline
\end{tabular}

experiments with different resistor values for each experiment was conducted, each resistor value was generating different time needed to first time constant (Table 1). Final value of pin capacitance is average from 3 different experiments.

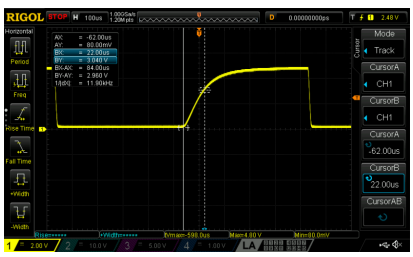

Fig. 6. Signal form with $20 \mathrm{k} \Omega \pm 5 \%$.

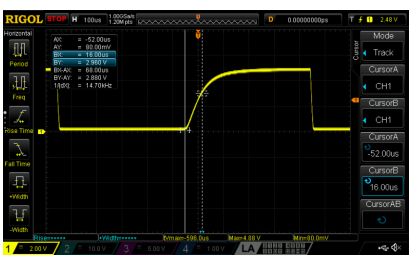

Fig. 7. Signal form with $15 \mathrm{k} \Omega \pm 5 \%$.

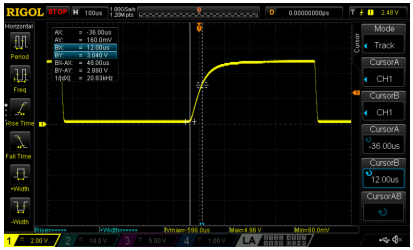

Fig. 8. Signal form with $10 \mathrm{k} \Omega \pm 5 \%$.

Shown on Figure 9, time to reach first time constant $(63 \%)$ is slower with increasing of pullup resistor value. Following Ohms law, higher Pull-up resistance also reduce current flowing thru. All current flow could be consider charging the pin 


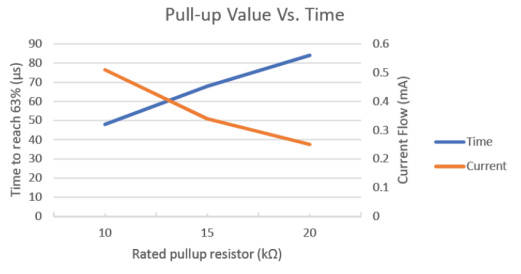

Fig. 9. Pull-up Value Vs. Time Vs. Current.

capacitance. Thus, lower resistance will cause bigger current flow, and faster to charge pin capacitors.

Using the formula to calculate the pull-up calculation.

$$
\begin{aligned}
R & =\frac{t}{0.9 C} \\
R & =1215,66 \Omega \\
R & \approx 1 K \Omega
\end{aligned}
$$

where: $t=5 \mu \mathrm{s}, C=4.57 \mathrm{nF}, R=$ Resistor value $(\Omega)$. By using $1 \mathrm{k} \Omega$ as pull-up resistor, there was no output signal on the other side of optocoupler (Figure 10). Signal were shown after replacing pull-up resistor into $470 \Omega$ (Figure 11).

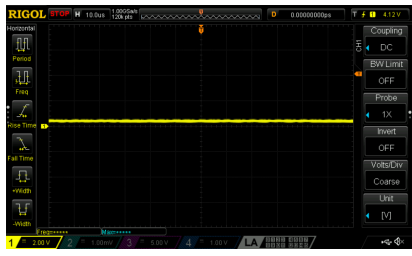

Fig. 10. Output Signal with $1 \mathrm{k} \Omega$ pull-up resistor.

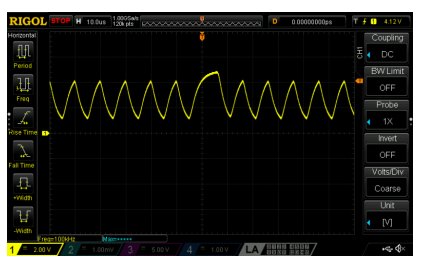

Fig. 11. Output Signal with $470 \Omega$ pull-up resistor.

\section{CONCLUSIONS}

In order coupling between encoder or other signal generator with Arduino via isolation devices such as optocoupler. Rise time form the signal me be considered, this signal must in certain voltage to giving input into the Arduino. Whole experiment shown that by adding pull-up resistors, system could be having faster rise time. It seems there are other factors beside the internal capacitance that effect the rise time, due to final testing result is not as expectation. $100 \mathrm{kHz}$ signal must be matched with lower pull-up resistor than calculated value, instead of using around $1 \mathrm{k} \Omega$ same with calculation.

\section{ACKNOWLEDGMENTS}

I acknowledge assistance or encouragement from colleagues.

\section{REFERENCES}

[1] Anon., 2018. RC Charging Circuit Tutorial \& RC Time Constant. [Online] Available at: https://www.electronics-tutorials.ws/rc/rc_1.html [Accessed 14 October 2018].

[2] Anon., 2018. The Basics of How an Encoder Works. s.l.:Company Encoder Products. Anon., n.d. Learn.sparkfun.com. [Online] Available at: https://learn.sparkfun.com/tutorials/logic-levels/ttl-logic-levels

[3] Anon., n.d. Understanding the Mathematics of Motion Control Profiles. [Online] Available at: https://www.pmdcorp.com/resources/ get/mathematics-of-motion-control-profilesarticle [Accessed 7 Febuary 2019]. 